\title{
Applicability of Environmental Landscape Diagnostic Methodologies Based on GIS
}

\author{
Enrique Valero ${ }^{1}$, Xana Álvarez ${ }^{1 *}$, Juan $\operatorname{Picos}^{1}$ and Fran Abilleira ${ }^{1}$
}

\begin{abstract}
:
This work has shown that using a methodology that considers complex variables such as Visual Fragility and Visual Quality, gives the possibility to establish a zoning including the landscape factor in spatial planning processes. In addition, it has shown that it is possible to adapt this general methodology to the specific circumstances of the area. The proposed model allowed its application in large, mid-scale or even in particular cases by the modification of the scale at which the source variables are obtained. For the three areas of study, there have been simulated 600 points of view including a population of 152,500 fixed observers and a million of mobile observers, systematically reinforced by 300 viewshed of densification. The calculation of Visual Fragility Acquired by superimposing a large number of viewshed reduced the subjectivity and provided a great consistency to the results. With the consistent and comparable results in three areas, taking into account their differences in topography, morphology, land use and population pressure, indicated that the model could be applied in almost all the coastal area of Galicia.
\end{abstract}

Keywords: geographic information systems, landscape planning, infrastructures effects

\section{Introduction}

Nowadays landscapes are on the political agenda. Natural and cultural aspects of landscapes receive increasing attention from researchers, planners and policy makers (Antrop, M., 2004). The landscape is constantly changing due to human activities in the territory (Piorr, 2003). This change is increase in speed and intensity a loss of values. In recent years, the environmental aspects are a general concern that affect all people in the world. Like all other human activities, the sport also affect environmental ecosystems. Therefore, previously installed a sport activities is necessary analyse the interactions with the environment. Analysing the landscape gets provide essential knowledge for management and protection. For this, should analyse always the natural and cultural components together, not separately. The landscape should be understand similarly to how the European Landscape Convention stated, as an area perceived by people, whose character is the result of interaction among natural factors and humans.

The landscape is conceived as a physical reality and the representation we have of it is the geographical morphology of a territory with all its natural and man-made elements with feelings and emotions aroused when contemplating them. During this stage, a good knowledge of the area and views was achieve. The trends experiences and dynamics affecting. The spatial modelling used by geographic information systems allow the

${ }^{1}$ AF4 Research Group. Engineering Department of Natural Resources and Environment, Forestry

Engineering College, University of Vigo, Campus a Xunqueira s/n, 36005 Pontevedra, Spain.

* Corresponding author. 
analysis of large volumes of territorial data, in a reasonable time with proper treatment of available information (Hernández, J. et al., 2004).

This paper is the design of a landscape analysis methodology based on GIS for landscape zoning criteria as landscaping fragility and planning of facilities, equipment and infrastructure within the landscape as a general goal, producing the least impact within the same.

\section{Material and Methods}

\section{a. Study Area}

We have selected three study areas with differences in topography, morphology, land use and population pressure. These areas are in Galicia, specifically in A Coruña (Camariñas and Porto do Son) and Lugo (Ribadeo) as is showed in Figure 1.

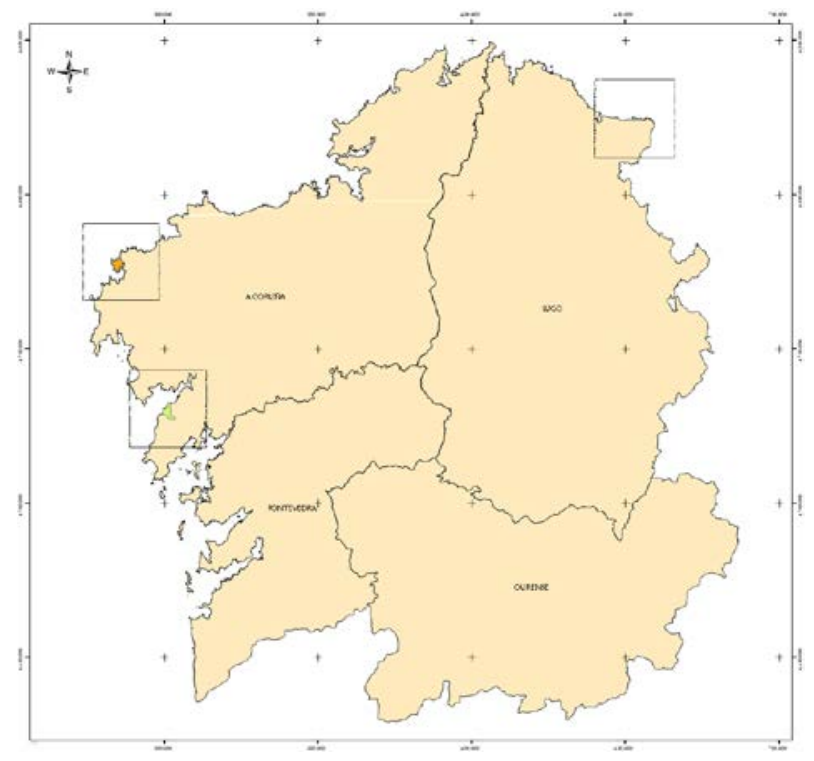

Figure 1. Area of study in Galicia (NW Spain).

\section{b. Information source}

The cartography that we used included different information layers such as communication networks (roads, railways, etc.), hydrography, boundaries and populations, landform, land uses and vegetation cover. The layers have been downloaded from SITGA (Territorial Information System of Galicia, in Spanish) and IGN (National Geographic Institute, in Spanish). This mapping was treat using the geographic information system ArcGIS at version 9.2. There is a schematization of the methodology in figure 2 . 


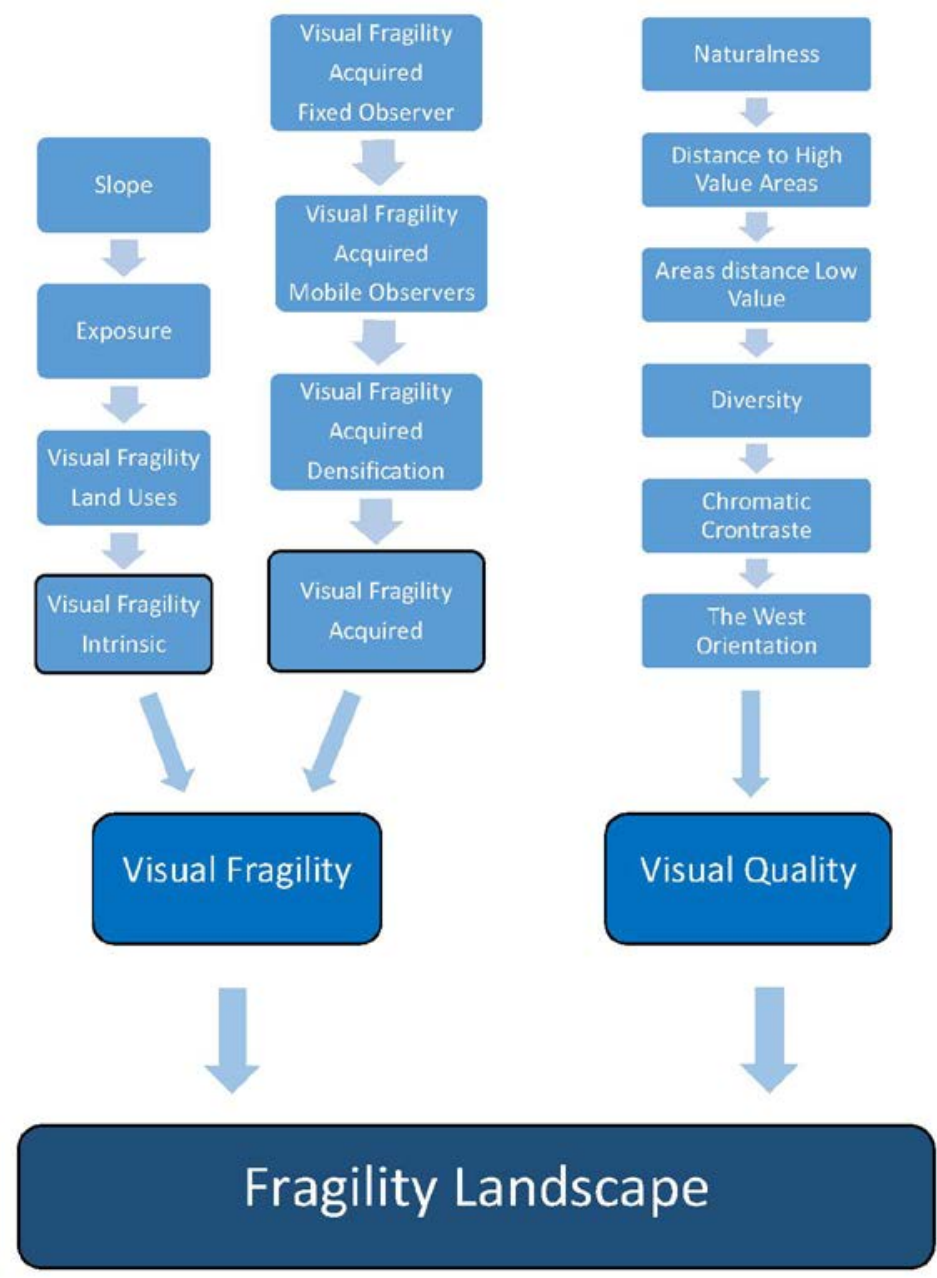

Figure 2. Schematic overview of the methodology.

\section{c. Visual fragility}

Landscape have not the same meaning for the population, and each one can have attributed different values and degrees, according to the agent, individual or group of people who perceive it. When we need or want to install a new area of sports facilities, is necessary to know the landscape of the territory in which it will be located. Therefore it should be analyse previously. This analysis was done with a GIS based tool that performs a zoning of the land taking into account the level of fragility. We have adapted and implemented some methodological concepts based on GIS obtained in previous researches.

To evaluate the visual fragility there was proposed a method inspired in López and Escribano (1999), considering the visual sensitivity as the sum of the intrinsic and 
acquired fragility, as defined below:

\section{i. Intrinsic visual fragility}

Martínez-Béjar and Martin-Rubio (1998) defined it as the presentation of a territory by its own characteristics and properties, taking into account biophysical factors (soil, vegetation cover, slope and aspect).

\section{F.V.I $=$ Slope $\cdot$ Exp $\cdot \mathrm{FVI}_{\text {land use }}$}

F.V.I.: Intrinsic visual fragility

Slope: Slope

Exp: Exposure

$\mathrm{FVI}_{\text {land use }}$ Visual Fragility attributed to land use at this point.

Slope is the eigenvalue of the slope obtained from the digital model of earrings in per unit. This factor multiplies the other terms of the equation, more slope equals more fragile, this is directly proportional to the slope of the land, whereas with more slope is more visible, as there is nothing between observer and the most remote points. The next term is the exposure, this is the second most important factor, four types of different orientations depending on their degree of importance within the fragility were proposed. An exhibition in which dominates the sun is much more fragile than one where the sun does not dominate, so it has more fragile land with sun exposure than one that does not. Finally, this visual fragility of land use varies according to the type of use. This time we worked with a vector layer of SITGA (Sistema de Información Territorial de Galicia), such as the land use, then convert to Raster and reclassify.

\section{ii. Visual fragility acquired}

To calculate the viewshed analysis was use. Therefore, a theoretical viewshed or potential can be defined as the set of all locations or points of territory that are visible from a particular point of observation with a maximum distance vision and the topography as limitation.

$$
F V A=\left[\frac{F V_{\text {obs. fixed }} \times F V_{\text {vías }} \times F V_{\text {densification }}}{3}\right] \times 10
$$


FVA (Fixed observer) selected nuclei of population with higher concentration in the studying and applying the theorem of Pareto, so the visual fragility of fixed observers is the sum of the viewshed " $\mathrm{n}$ " fixed points and function of their distance from the area study of concrete viewshed (CV) and the existing population at the core (P)

$$
\underset{\text { obs.fijos }}{F V}=\sum_{i=1}^{n}\left(d_{i} * C V_{i} * P_{i}\right)
$$

F.V.A: Visual fragility acquired

$\mathrm{P}_{\mathrm{i}}$ : Weighting (Population or Affluence)

$\mathrm{CV}_{\mathrm{i}}$ : Memberships Cuenca Visual point $\mathrm{i}$

$\mathrm{d}_{\mathrm{i}}$ : Distance observation

FVA (Mobile observers) theoretical observers were place in existing channels of communication within $12 \mathrm{~km}$ of the study area.

$$
F \underset{\text { vias }}{V A}=\sum_{j=1}^{n}\left(d_{j} * C V_{j} * T_{i}\right)
$$

F.V.A: Visual fragility acquired

$\mathrm{T}_{\mathrm{i}}$ : Average daily traffic

$\mathrm{CV}_{\mathrm{j}}$ : Pertenencia a Cuenca Visual del punto i

dj: Distance observation

FVA (Densification) a mesh was create considering all observers, marine and terrestrial. Those places in the sea have a weighting factor of 25 . The points located on the ground a weighting factor of 100 .

$$
\operatorname{Int}\left[\frac{1.000 \cdot\left[25 \cdot \sum_{i=1}^{m} C V_{i} \cdot d_{i}+100 \cdot \sum_{j=1}^{t} C V_{j} \cdot d_{j}\right]}{m+t}\right]
$$


m: crosslinked nodes at sea

t: grid nodes ground

$\mathrm{CV}_{\mathrm{i}}$ : a factor belonging to the visual point node basin $\mathrm{i}(0,1)$

$\mathrm{d}_{\mathrm{i}}$ : correction factor of the observation distance from node $\mathrm{i}$

Int: integer part

\section{b. Visual quality}

This quality was appreciate and recognized differently by each observer. This was condition by the sensory and perceptual mechanisms inherent to the observer. Just as culture, education and the relationship of the observer with the landscape. For this work independence between the results and the people who developed it as one of the objectives to be met. The formula was used

$$
\text { Quality }=3 \cdot \mathrm{Val}_{\mathrm{pai}}+1,5 \cdot \operatorname{Prox}_{\mathrm{v} 5}+1,5 \cdot \operatorname{Prox}_{\mathrm{v} 1}+2 \cdot \operatorname{Div}_{\mathrm{pai}}+\mathrm{C}_{\mathrm{crom}}+\mathrm{Or}_{\mathrm{w}}
$$

Landscape value (Val pai) states that the quality of a landscape is greater the more naturally be, and more naturally with less human intervention. The most natural areas take maximum values (value 5 red) and lower zones we naturally take minimum values (value 1 green). Factor proximity to areas of high value (Proxv5) to select the next few value 5 in the above factor as the most natural areas. The proximity to areas of lower value (Proxv1) evaluated the impacts capable of reducing the visual quality of the surrounding landscape, visual impacts was consider quarry or opencast mines, large population centers and industrial, commercial and service areas The diversity (Div pai) assesses the degree of mosaic of uses in the landscape, considered that the quality increases proportionally with increasing diversity. The next factor, seasonal contrast colours (Ccrom) think that a land use possessing contrasting colours in different seasons possess a higher visual quality. Finally, setting the orientation (Orw) this factor is included as increase the visual quality of a point as its direction is nearer to the west. This factor has been included for the effect it creates light late in the coastal area, especially at sunset.

\section{d. Final zoning}

Finally, the visual sensitivity and visual quality was combine in the following formula.

$$
0,6 \cdot \mathrm{FV}+0,4 \cdot \mathrm{CV}
$$

Thus, the results was obtain by categories 1 to 5 , representing low to high landscape fragility. This method analyses the landscape and get a zoning of the territory according 
to the degree of landscape fragility. The land is zoned into five levels of frailty, representing level 1 (coloured dark green) areas of low landscape fragility and level 5 (coloured red) areas of high landscape fragility. Given this quality objectives landscape given in Table were determined.

Table 1. Quality objectives for each level of landscape fragility.

\begin{tabular}{|l|l|l|}
\hline \multicolumn{2}{|l|}{ LANDSCAPING FRAGILITY } & QUALITY OBJECTIVES \\
\hline 1 & Very low & Improve / Creating new landscape \\
\hline 2 & Low & Restore / Improve \\
\hline 3 & Means & Preserve / Restore \\
\hline 4 & High & Conservation and maintenance \\
\hline 5 & Very high & Conservation and maintenance \\
\hline
\end{tabular}

\section{e. Results and Discussion}

This work shows that using a methodology that includes complex variables as Visual Fragility and Visual Quality, establish a zoning that takes into account the landscape when making decisions variables. You can adapt this general methodology to the specific circumstances of any infrastructure and planned event. The proposed model, just change the scale at which the source variables are obtain their application in wide areas as well as in small areas or particular cases of buildings or projects.

In the three areas of study in this work 600 points of vision including a fixed population of 152,500 and a million watchers mobile observers systematically reinforced by 300 viewshed densification were simulate. Obtaining consistent and comparable results in three areas with marked differences in topography, morphology, land use and anthropogenic pressure, indicating that the model could be apply to the entire area of Galicia.

For the exhibition, factor included in the intrinsic visual fragility and after carefully study the difference of the same performance as a function of exposure terrain (Table 1), the following was propose as possible values of this factor in the equation.

Table 2. Exposure terrain value.

\begin{tabular}{|l|l|}
\hline Exposure & Value \\
\hline Shadow & 1 \\
\hline Sunny middle east & 1.05 \\
\hline Sunny middle west & 1.15 \\
\hline Sunny & 1.25 \\
\hline
\end{tabular}


Regarding the visual fragility densification acquired, the covariance matrix for all points studied in the three study areas was calculate. Finally, 2,500m mesh width is 100 visual chose to consider basins (Table 2).

Table 3. Covariance matrix pair the set of points studied.

\begin{tabular}{|l|l|l|l|l|l|}
\multicolumn{1}{c|}{} & 1,000 & 2,000 & 2,500 & 3,000 & 6,000 \\
\hline 1,000 & 1 & 0.83022 & 0.8979 & 0.88421 & 0.86526 \\
\cline { 2 - 6 } 2,000 & 0.83022 & 1 & 0.69809 & 0.68736 & 0.70998 \\
\hline 2,500 & 0.89790 & 0.69809 & 1 & 0.96721 & 0.88251 \\
\cline { 2 - 6 } 3,000 & 0.88421 & 0.68736 & 0.96721 & 1 & 0.89093 \\
\hline 6,000 & 0.86526 & 0.70998 & 0.88251 & 0.89093 & 1 \\
\hline
\end{tabular}

As an example of result, corresponding figures show a particular area of the three in which the study was conduct. This is located in the town of Camarinas, province of A Coruña.
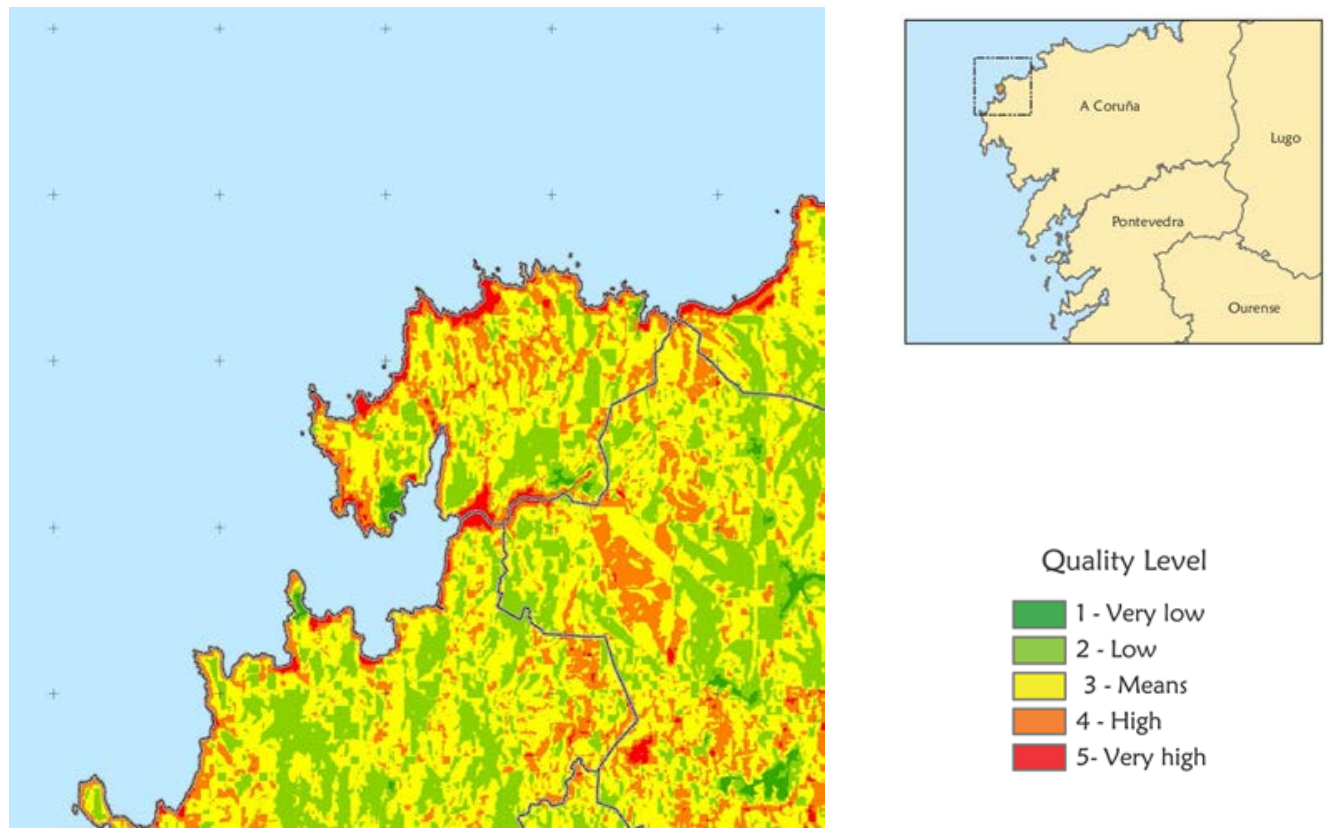

Figure 3. Visual quality of Camariñas. 

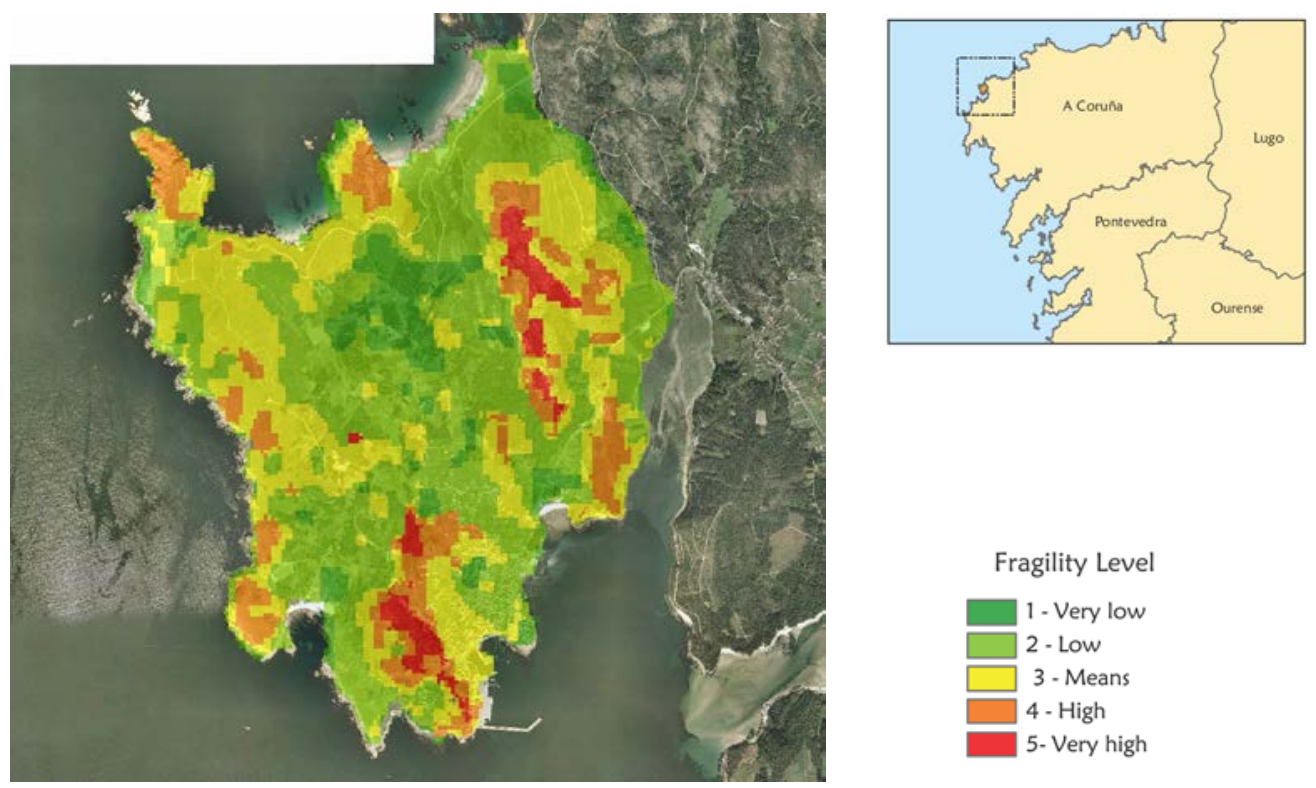

Figure 4. Visual fragility of Camarinas on orthophoto.

As a result we obtained Figure 6 with the final zoning where landscaping fragile Ascending shown.
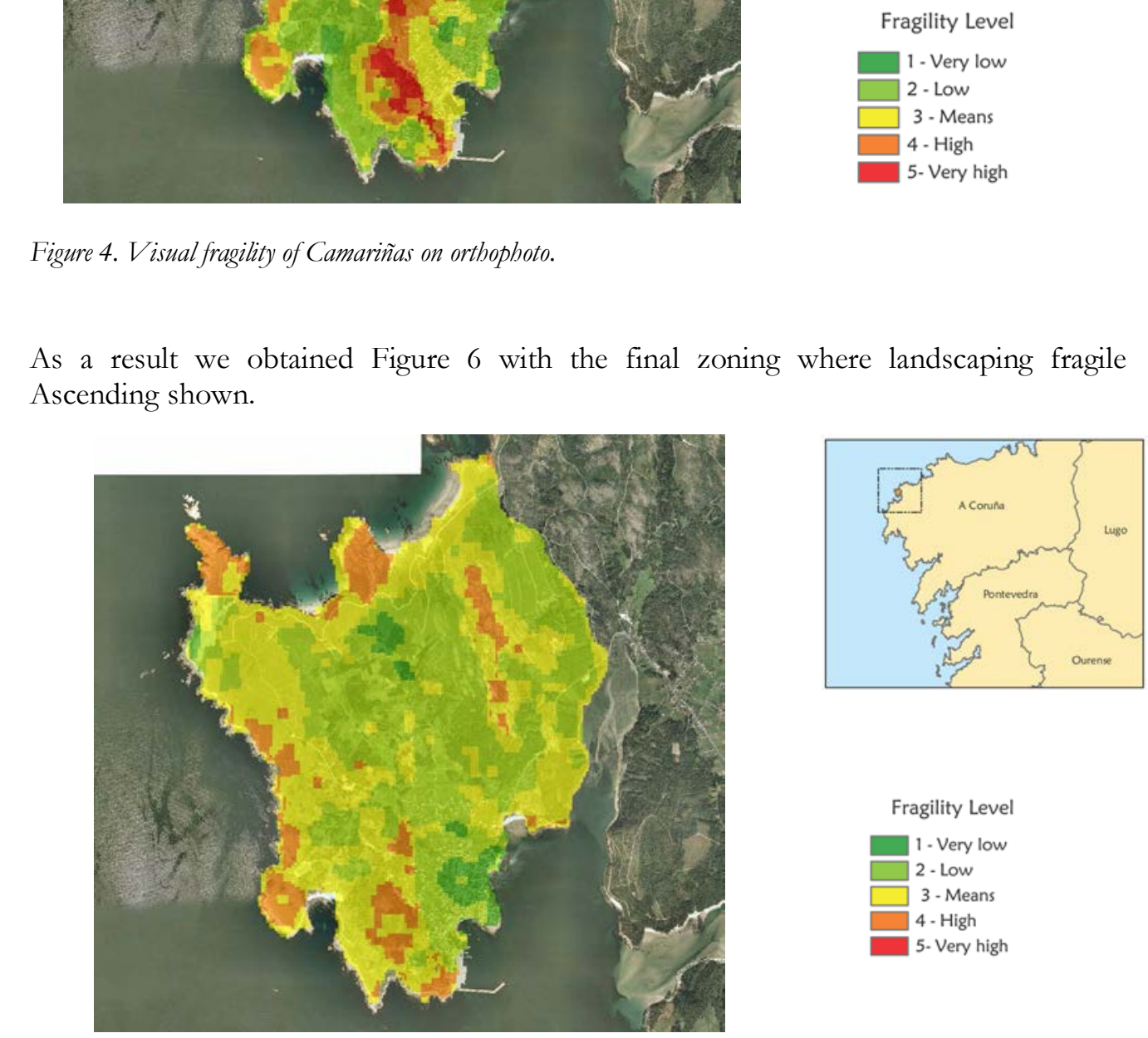

Figure 5. Landscaping fragility final zoning according to the study area of Camarinas.

\section{Fragility Level}

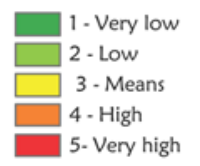




\section{Conclusion}

Obtaining consistent and comparable results in three areas with large differences orography, morphology, land use and population pressure, concludes that the model can be apply to the entire area of Galicia. One of the keys in the generation of the model was the minimization of the subjectivity inherent to the operator. Thus, the created model can evolve easily take measures as consideration of the phenomena of concealment, the weighting of the past evolution of land use among other factors.

At work I developed, this methodology demonstrated its sensitivity and efficiency in continuous improvement processes for adapting and optimizing classification criteria and possible use of other parameters. It is therefore advisable to persevere in the application thereof and the feedback model with the results and its transposition to the territory. This methodology should be accompanied to achieve minimize negative effects on the landscape. Therefore, after evaluation of fragility of the landscape should be set landscape quality objectives to determine where each zone must evolve.

Finally establish a set of criteria and recommendations will nativity scenes to follow to achieve the objectives. Consequently, we will get locate and integrate the relevant infrastructure in the environment producing a minimal impact on the landscape.

\section{References}

Antrop, M. (2004). Landscape change and the urbanization process in Europe. Landscape and urban planning, 67(1), 9-26.

Gonzalo, L. R., \& MP Aramburu Maqua, R. (2005, June). Control visual del territorio: Predicción y análisis de los impactos sobre el paisaje. In Congresos Forestales.

Hernández, J., Garcia, L., \& Ayuga, F. (2004). Integration methodologies for visual impact assessment of rural buildings by geographic information systems. Biosystems Engineering, 88(2), 255-263.

Martínez-Béjar, R., \& Martin-Rubio, F. (1998). Landscape: A knowledge-based system for visual landscape assessment. In Tasks and Methods in Applied Artificial Intelligence (pp. 849-856). Springer Berlin Heidelberg.

Piorr, H. P. (2003). Environmental policy, agri-environmental indicators and landscape indicators. Agriculture, Ecosystems \& Environment, 98(1), 17-33.

SITGA (Sistema de Información Territorial de Galicia), Consellería de Medio Ambiente, Territorio e Infraestructuras (2015) http://mapas.xunta.es/portada

IGN (Instituto Geográfico Nacional). Ministerio de Fomento, (2015) http://www.ign.es/ign/main/index.do 